\title{
Behaviour of metakaolin-based geopolymers incorporating sewage sludge ash (SSA)
}

\author{
D.B. Istuque ${ }^{\text {a }}$, L. Reig ${ }^{\mathrm{b}}$, J.C.B. Moraes ${ }^{\text {a }}$, J.L. Akasaki ${ }^{\mathrm{a}}$, M.V. Borrachero ${ }^{\mathrm{c}}$, L. Soriano ${ }^{\text {, }}$, J. Payá ${ }^{\mathrm{c}}$, \\ J.A. Malmonge ${ }^{\mathrm{a}}$, M.M. Tashima ${ }^{\mathrm{a}, *}$ \\ ${ }^{a}$ UNESP - Univ Estadual Paulista, Campus de Ilha Solteira, São Paulo, Brazil \\ ${ }^{\mathrm{b}}$ EMC, Universitat Jaume I, Castelló de la Plana, Spain \\ c ICITECH - Instituto de Ciencia y Tecnología del Hormigón, Universitat Politècnica de Valencia, Valencia, Spain
}

\section{A R T I C L E I N F O}

Article history:

Received 5 February 2016

Received in revised form

2 May 2016

Accepted 28 May 2016

Available online 30 May 2016

Keywords:

Alkali-activated binder

Microstructure

Residue

$\mathrm{X}$-ray techniques

\begin{abstract}
A B S T R A C T
In recent years, geopolymers have become a widely researched binding material. There are technological and environmental advantages to using this type of binder instead of Portland cement. In this study, binary systems of geopolymers were produced by using mixtures of metakaolin (MK), a well-known aluminosilicate raw material, and a residue from sewage sludge incineration: sewage sludge ash (SSA). This ash was used to partially replace the metakaolin in proportions of $0-20 \%$. The mixtures were activated with alkaline solutions and they were cured by using two different conditions: at room temperature $\left(25^{\circ} \mathrm{C}\right)$ and in a thermal bath $\left(65^{\circ} \mathrm{C}\right)$. The samples were assessed by X-ray diffraction, scanning electron microscopy (pastes) and compressive strength (mortars). The results from these studies showed zeolite formation (faujasite) in geopolymers cured in the thermal bath, which caused a decrease in the compressive strength of the alkali-activated mortars. Replacement of MK with SSA caused a lower reduction in the compressive strength of mortars cured at $65{ }^{\circ} \mathrm{C}$. However, at room temperature, similar mechanical strength was observed for the MK and MK-SSA systems. These results demonstrated that SSA is a suitable mineral precursor for partial replacement of MK in geopolymer production.
\end{abstract}

(c) 2016 Elsevier B.V. All rights reserved.

\section{Introduction}

Geopolymers are a new class of material obtained by a chemical reaction of an aluminosilicate material and a highly concentrated alkaline solution [1]. This binding material can be used as a construction material due to their high strength and durability, replacing Portland cement (OPC) in concrete [2].

Metakaolin (MK) is usually used as the aluminosilicate source in geopolymers [3-5]. Previously studies on metakaolin-based geopolymers have shown high compressive strength after a few hours of curing at temperatures ranging from 40 to $95^{\circ} \mathrm{C}$ [3]. However, research has shown that some geopolymers, especially metakaolin-based ones cured at high temperatures, tend to form crystalline structures: zeolites [6-9]. These crystalline phases significantly reduce the compressive strength of geopolymers, a critical behaviour for building materials $[2,9]$.

In this sense, the combination of different raw materials containing silicon and/or aluminium oxides on their composition are being carried out (binary systems) in order to reduce the zeolite

\footnotetext{
* Corresponding author.

E-mail address: maumitta@hotmail.com (M.M. Tashima).
}

formation [10,11]. Sewage sludge ash (SSA), a waste generated in large amounts (1.7million tons per year) has been studied extensively in blended Portland cements [12-14]. The first study related to the use of SSA in geopolymers were reported by Yamaguchi et al. where authors used fly ash/SSA yielding the maximum flexural strength (about $5.5 \mathrm{MPa}$ ) for mixture containing 75\%SSA [15].

In this paper is presented the influence of SSA on the mechanical strength and on the crystallization process (zeolite formation) of metakaolin-based geopolymers. Specimens were cured at both high-temperature and $25^{\circ} \mathrm{C}$ and they were assessed through compressive strength, X-ray diffraction and scanning electron microscopy.

\section{Materials and methods}

\subsection{Materials and equipment}

Metakaolin was supplied by Metacaulim do Brasil ${ }^{\mathbb{R}}$. Sewage sludge ash was obtained from an auto-combustion process of sewage sludge from São José do Rio Preto city (São Paulo-Brazil). The chemical composition of MK and SSA are shown in Table 1. 
Table 1.

Chemical composition of MK and SSA in percentage by mass.

\begin{tabular}{|c|c|c|c|c|c|c|c|c|c|c|c|}
\hline Oxide (\%) & $\mathrm{SiO}_{2}$ & $\mathrm{Al}_{2} \mathrm{O}_{3}$ & $\mathrm{Fe}_{2} \mathrm{O}_{3}$ & $\mathrm{CaO}$ & MgO & $\mathrm{Na}_{2} \mathrm{O}$ & $\mathbf{K}_{\mathbf{2}} \mathbf{O}$ & $\mathrm{SO}_{3}$ & $\mathrm{TiO}_{2}$ & Others & LOI \\
\hline MK & 58.39 & 35.47 & 2.71 & 0.01 & 0.30 & - & 1.44 & - & 1.51 & 0.07 & 0.10 \\
\hline SSA & 38.28 & 20.72 & 11.27 & 5.51 & 1.91 & 0.70 & 0.73 & 4.18 & 3.73 & 9.25 & 3.72 \\
\hline
\end{tabular}

The mean particle diameter, $\mathrm{d}_{50}$ and $\mathrm{d}_{90}$ of MK were 23.90, 18.16 and $53.96 \mu \mathrm{m}$, respectively; and for SSA they were 20.28, 11.77 and $52.45 \mu \mathrm{m}$, respectively. For mortar preparation, siliceous sand (Castilho city, São Paulo-Brazil) with a fineness modulus of 2.05 and specific gravity of $2.67 \mathrm{ton} / \mathrm{m}^{3}$ was used. Sodium hydroxide (98\% purity) and sodium silicate $\left(18 \% \mathrm{Na}_{2} \mathrm{O}, 63 \% \mathrm{SiO}_{2}\right)$ were used for the preparation of alkaline solutions (both supplied by Dinâmica Química).

X-ray diffraction (XRD) patterns for raw materials and geopolymeric pastes were obtained using a Shimadzu XRD-6000 system. The $2 \theta$ range was $5-60^{\circ}$ using $\mathrm{Cu}-\mathrm{K} \alpha$ radiation and a Ni filter, at a voltage of $30 \mathrm{kV}$, a current intensity of $40 \mathrm{~mA}$, an angle step of $0.02^{\circ}$, and a step time of $1.20 \mathrm{~s} / \mathrm{step}$. Scanning electron microscopy (SEM) images of fractured surface pastes were obtained using a ZEISS model EVO LS15. The compressive strength of mortars was measured in an EMIC Universal machine with a 200-ton load limit.

\subsection{Geopolymer preparation}

Three different proportions of MK replacement by SSA were assessed in this study: $0 \%$ (control), $10 \%$ and 20\% (by mass). The $\mathrm{H}_{2} \mathrm{O} / \mathrm{Na}_{2} \mathrm{O}$ and $\mathrm{SiO}_{2} / \mathrm{Na}_{2} \mathrm{O}$ molar ratios were maintained constant at 9.26 and 2.00, respectively. For mortars, the sand/binder ratio was 2.5 (the binder amount being the sum of the masses of MK and SSA). Two different curing temperatures were applied at a relative humidity greater than $95 \%: 25{ }^{\circ} \mathrm{C}$ (room temperature) and $65{ }^{\circ} \mathrm{C}$ (using a thermal bath). The compressive strength of the mortars was determined after one, three and seven days of curing. XRD studies were performed on pastes after the same curing times. SEM studies were performed only after three days of curing.

The samples used in this paper are named as MKc- $x x$, where $c$ is the curing temperature $(c, \mathrm{R}$ : room temperature, $\mathrm{B}$ : thermal bath) and $\mathrm{xx}$ is the percentage of SSA incorporated ( $x x=0,10$ or 20).

\section{Results and discussion}

The compressive strengths of the different mortars are shown in Fig. 1. For mortars cured at $65^{\circ} \mathrm{C}$ (Fig. 1a), the compressive strength of all mixtures decreased with increasing curing time. Similarly, the strength of the mortars after one day of curing at $65{ }^{\circ} \mathrm{C}$ decreased with increasing replacement of MK by SSA. After three days of curing at $65{ }^{\circ} \mathrm{C}$ the compressive strength of the mortars decreased by $34 \%$ for MKB-0, 36\% for MKB-10\% and $37 \%$ for MKB-20. The compressive strength of mixtures incorporating 10 or $20 \%$ of SSA decreased by a similar percentage as the control (MKB-0, 36\%). After seven days of curing, the compressive strength values and their respective percentage loss of compressive strength compared to the values after three days of curing were 20.3 MPa (16.8\%), 16.6 MPa (12.6\%) and 15.0 MPa (9.1\%) for MKB-0, MKB-10 and MKB-20, respectively. These results show that the relative decrease in compressive strength with curing time is lower in mortars containing up to 20\% SSA than in the control sample. These results suggest that the use of SSA in the production of metakaolin-based geopolymers stabilizes the compressive strength in mortars prepared with long curing times.

Mortars cured at room temperature (Fig. 1b) behaved

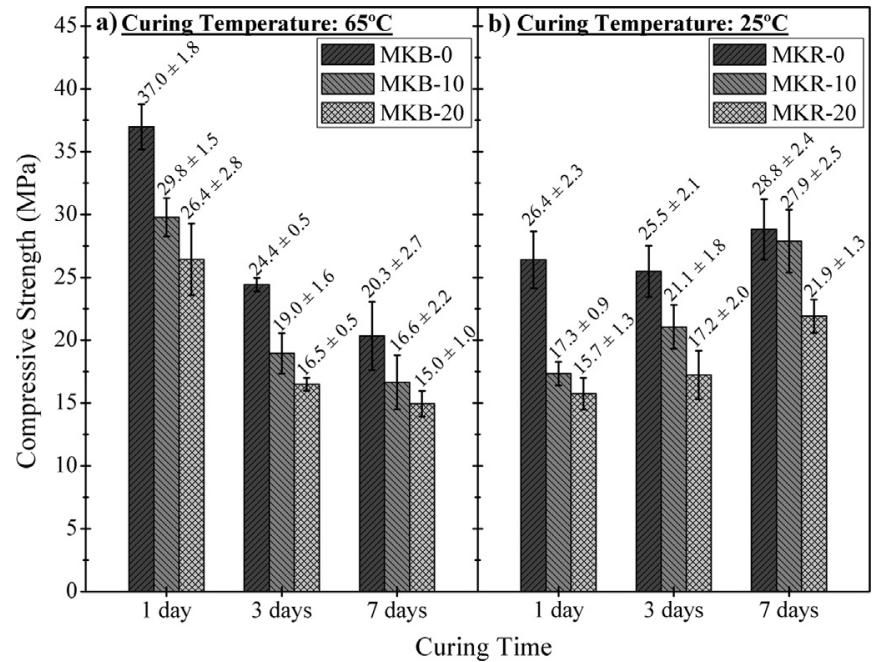

Fig. 1. Compressive strength of mortars: a) cured at $65^{\circ} \mathrm{C}$; and b) cured at $25^{\circ} \mathrm{C}$.

differently to samples cured at $65^{\circ} \mathrm{C}$. At room temperature, mortars did not show a decrease in compressive strength with curing time. After one day of curing at room temperature, the strength decreased when SSA content was increased, similar to the situation for mortars cured at $65^{\circ} \mathrm{C}$. After three and seven days of curing, the compressive strength of MKR-0 increased slightly, whereas samples incorporating SSA presented an important strength gain. After seven days of curing at room temperature, the MKR-10 sample achieved a similar strength to MKR-0 (27.9 and 28.8 MPa, respectively). This result suggests that the use of SSA in metakaolin-based geopolymers may be an interesting possibility.

XRD studies were carried out on MKB-0, MKB-20, MKR-0 and MKR20 pastes in order to examine the formation of crystalline phases, both at $25^{\circ} \mathrm{C}$ and $65^{\circ} \mathrm{C}$ (Fig. 2). The raw materials MK and SSA show a baseline deviation in the range $16-32^{\circ}$ and $18-32^{\circ}$, respectively, which is

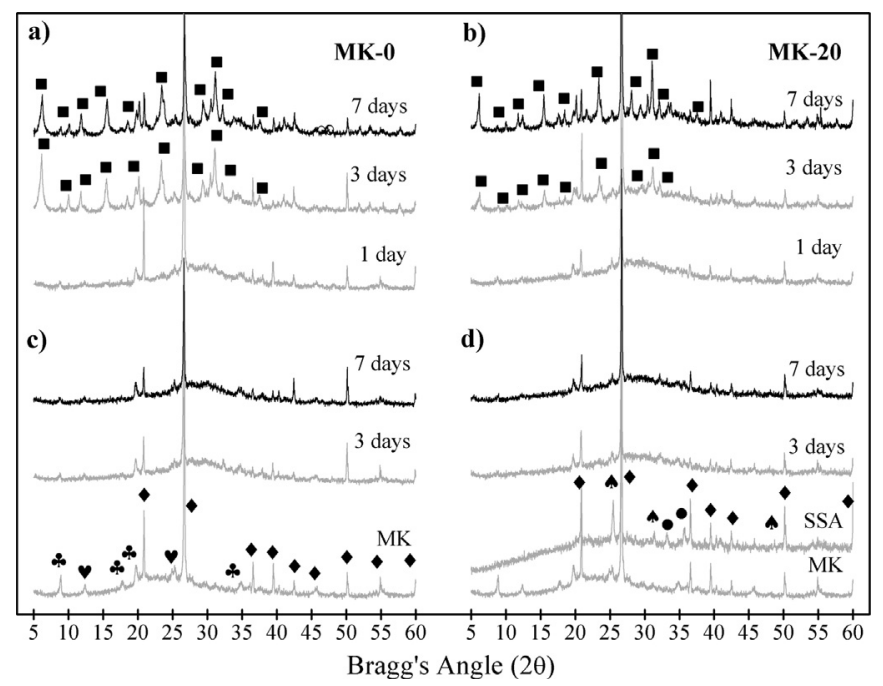

Fig. 2. XRD patterns for MK/SSA pastes: a) MKB-0; b) MKB-20; c) MKR-0; d) MKR-

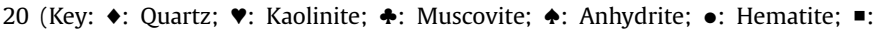
Faujasite). 

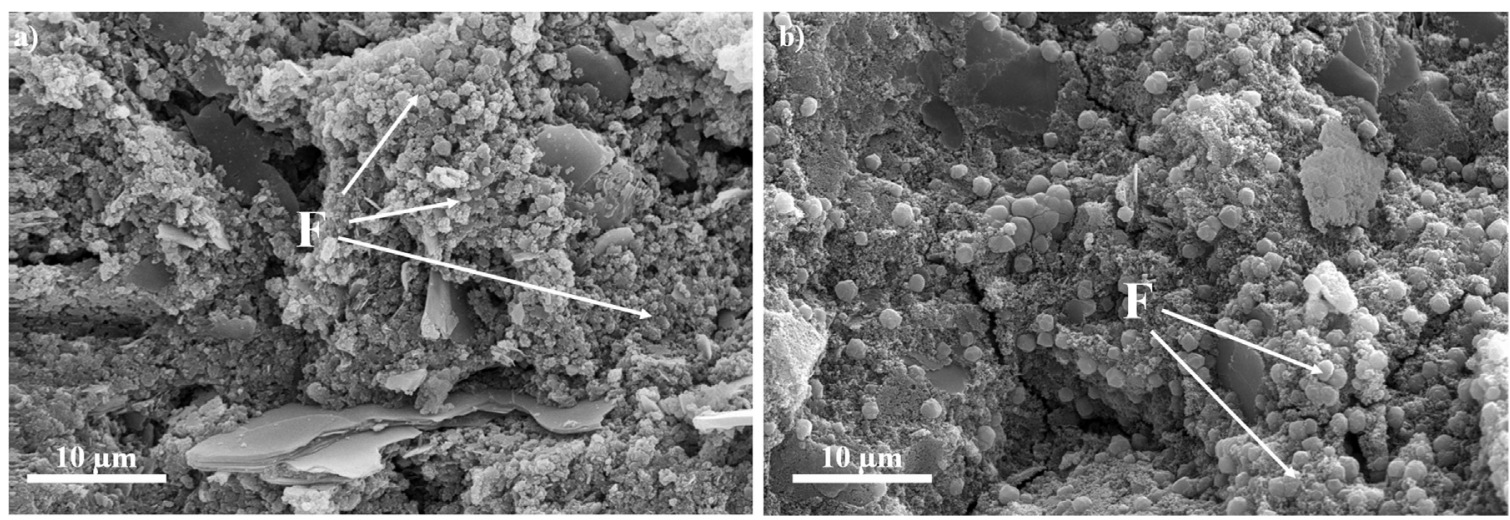

Fig. 3. SEM micrographs of geopolymer fractured surfaces: a) MKB-0; b) MKB-20 (Key: F- faujasite).

characteristic of the presence of an amorphous phase. Quartz ( $\mathrm{SiO}_{2}$, PDFcard\#331161), kaolinite $\left(\mathrm{Al}_{2} \mathrm{Si}_{2} \mathrm{O}_{5}(\mathrm{OH})_{4}\right.$, PDFcard\#140164) and muscovite $\left(\mathrm{KAl}_{3} \mathrm{Si}_{3} \mathrm{O}_{10}(\mathrm{OH})_{2}\right.$, PDFcard\#210993) were found in $\mathrm{MK}$, and quartz, anhydrite ( $\mathrm{CaSO}_{4}$, PDFcard\#371496), anorthite $\left(\mathrm{CaAl}_{2} \mathrm{Si}_{2} \mathrm{O}_{8}\right.$, PDFcard\#411486) and hematite $\left(\mathrm{Fe}_{2} \mathrm{O}_{3}\right.$, PDFcard\#130534) were found in SSA.

For the geopolymeric pastes, all samples presented a baseline deviation line between 16 and $40^{\circ}$, which can be attributed to the amorphous phase of the geopolymeric gels. This shift of the baseline to higher $2 \theta$ values compared to the MK and SSA amorphous phases due the geopolymerisation reaction has also been observed in others studies [16]. For pastes cured at $65{ }^{\circ} \mathrm{C}$, faujasite $\left(\mathrm{Na}_{2} \mathrm{Al}_{2} \mathrm{Si}_{4} \mathrm{O}_{12} \cdot 8 \mathrm{H}_{2} \mathrm{O}\right.$, PDFcard\#391380) formation was observed after three days of curing (Fig. 2a and b). However, the presence of SSA influences the zeolite formation, since a lower zeolite peak intensity is observed after three days of curing at $65{ }^{\circ} \mathrm{C}$ compared to MKB-0. No signals attributed to zeolites were distinguished by XRD analyses on pastes cured at room temperature, either in MKR0 (Fig. 2c) or MKR-20 (Fig. 2d), whatever the curing time (three and seven days).

Both geopolymeric gel and zeolite formation are directly related to the reactivity of the raw materials and to the curing temperature $[2,17]$. For high alkaline environment, high curingtemperatures favours the crystallization of aluminosilicate gels forming zeolite-type structures and, according to Bosnar et al., the crystallization process is sharply reduced with the increase on the $\mathrm{SiO}_{2} / \mathrm{H}_{2} \mathrm{O}$ [17]. In this paper, $\mathrm{MK}$ presented higher reactivity than SSA, so it was expected that geopolymers with higher amounts of MK would present more intense zeolite formation and, consequently, greater reduction in compressive strength. It is due to the microporous-crystalline structure based on 3D-cage system of zeolites that reduces the compressive strength of mortars when compared to the amorphous structure based on 3D-network of aluminate and silicate tetrahedral of geopolymers $[2,18]$.

Faujasite was also observed in SEM on fractured samples of MKB-0 and MKB-20 after three days of curing (Fig. 3). Rounded crystalline particles of $2-4 \mu \mathrm{m}$ size were formed. Since the raw material mainly contains metakaolin, faujasite was formed in both pastes.

\section{Conclusion}

Metakaolin-based geopolymers with partial replacement of MK with SSA were studied. XRD analysis showed that geopolymers cured at $65{ }^{\circ} \mathrm{C}$ produced faujasite after three days of curing. This zeolite formation caused a decrease in compressive strength with the curing age at $65^{\circ} \mathrm{C}$. The addition of SSA (up to 20\%) to the mixture resulted in a smaller loss of compressive strength in mortars cured at $65{ }^{\circ} \mathrm{C}$ when compared to the control without SSA. In addition, in samples cured at $25^{\circ} \mathrm{C}$, those containing $10 \%$ SSA presented similar compressive strength as the control mortar after seven days of curing. Thus partial replacement of metakaolin with SSA showed advantages in both curing conditions.

\section{Acknowledgments}

The authors acknowledge Santander Universidades for the grant to Lucia Reig (program: Becas Iberoamérica Jóvenes Profesores Investigadores España 2014), CAPES (CAPES/DGU n²66/12), CNPq (no. 14/2013 processo 478057/2013-0) Scanning electron microscopy service of FEIS/UNESP and CNPq (processo 309015/ 2015-4).

\section{References}

[1] P. Duxson, A. Fernández-Jiménez, J.L. Provis, G.C. Lukey, A. Palomo, J.S.J. van Deventer, Geopolymer technology: the current state of the art, J. Mater. Sci. 42 (2007) 2917-2933.

[2] J.L. Provis, J.S.J. van Deventer, Geopolymers: Structure, Processing, Properties and Industrial Applications, first ed., Woodhead Publishing Limited, Oxford, 2009.

[3] M.S. Muñiz-Villarreal, A. Manzano-Ramírez, S. Sampieri-Bulbarela, J.R. Gasca-Tirado, J.L. Reyes-Araiza, J.C. Rubio-Ávalos, J.J. Pérez-Bueno, L.M. Apatiga, A. ZaldivarCadena, V. Amigó-Borrás, The effect of temperature on the geopolymerization process of a metakaolin-based geopolymer, Mater. Lett. 65 (2011) 995-998.

[4] C. Kuenzel, T.P. Neville, S. Donatello, L. Vandeperre, A.R. Boccaccini, C. R. Cheeseman, Influence of metakaolin characteristics on the mechanical properties of geopolymers, Appl. Clay Sci. 83-84 (2013) 308-314.

[5] M.R. Wang, F.C. Jia, P.G. He, Y. Zhou, Influence of calcination temperature of kaolin on the structure and properties of final geopolymer, Mater. Lett. 64 (2010) 2551-2554.

[6] J. Zhang, Y. He, Y. Wang, J. Mao, X. Cui, Synthesis of a self-supporting faujasite zeolite membrane using geopolymer gel for separation of alcohol/water mixture, Mater. Lett. 116 (2014) 167-170.

[7] N. Granizo, A. Palomo, A. Fernandez-Jiménez, Effect of temperature and alkaline concentration on metakaolin leaching kinetics, Ceram. Int. 40 (2014) 8975-8985.

[8] H. Takeda, S. Hashimoto, H. Yokoyama, S. Honda, Y. Iwamoto, Characterization of zeolite in zeolite-geopolymer hybrid bulk materials derived from kaolinitic clays, Materials 6 (2013) 1767-1778.

[9] T. Bakharev, Geopolymeric materials prepared using Class F fly ash and elevated temperature curing, Cem. Concr. Res. 35 (2005) 1224-1232.

[10] Z. Zhang, H. Wang, Y. Zhu, A. Reid, J.L. Provis, F. Bullen, Using fly ash to partially substitute metakaolin in geopolymer synthesis, Appl. Clay Sci. 88-89 (2014) 194-201.

[11] S. Yan, K. Sagoe-Crentsil, Properties of wastepaper sludge in geopolymer mortars for mansory applications, J. Environ. Manag. 112 (2012) 27-32.

[12] S. Donatello, C.R. Cheeseman, Recycling and recovery routes for incinerated sewage sludge ash (ISSA): a review), Waste Manag. 33 (2013) 2928-2940.

[13] B.J. Zhan, C.S. Poon, Study on feasibility of reutilizing textile effluent sludge for producing concrete blocks, J. Clean. Prod. 101 (2015) 174-179.

[14] M. Cry, R. Idir, G. Escadeillas, Use of metakaolin to stabilize sewage sludge ash and municipal solid waste incineration fly ash in cement-based materials, J. Hazard. Mater. 243 (2012) 193-203. 
[15] N. Yamaguchi, K. Ikeda, Preparation of geopolymeric materials from sewage sludge slag with special emphasis to the matrix compositions, J. Ceram. Soc Jpn. 118 (2010) 107-112.

[16] M.M. Tashima, J.L. Akasaki, J.L.P. Melges, L. Soriano, J. Monzó, J. Payá, M. V. Borrachero, Alkali activated materials based on fluid catalytic cracking catalyst residue (FCC): influence of $\mathrm{SiO}_{2} / \mathrm{Na}_{2} \mathrm{O}$ and $\mathrm{H}_{2} \mathrm{O} / \mathrm{FCC}$ ratio on mechanical strength and microstructure, Fuel 108 (2013) 833-839.
[17] S. Bosnar, J. Bronic, D. Brlek, B. Subotic, Chemically controlled particulate properties of zeolites: towards the face-less particles of zeolite A. 2. Influence of aluminosilicate batch concentration and alkalinity of the reaction mixture (hydrogel) on the size and shape of zeolite A crystals, Microporous Mesoporous Mater. 142 (2011) 389-397.

[18] J. Li, A. Corma, J. Yu, Synthesis of new zeolite structures, Chem. Soc. Rev. 44 (2015) 7112-7127. 